\title{
Russia's Quality Higher Education on the Global Agenda of Sustainable Development
}

\author{
Elena Kulikova*, Olga Durandina and Elena Molokova \\ Ural State University of Economics, Yekaterinburg, Russia
}

\begin{abstract}
Nowadays, many countries are searching for the best models of higher education that can ensure the implementation of the Sustainable Development Goals. In the context of the Global Development Agenda, education is considered as a spatial system that has the potential to increase the effectiveness of harmonizing economic, social and environmental aspects of human life. The paper correlates the objectives of the fourth Sustainable Development Goal "Ensure inclusive and equitable quality education and promote lifelong learning opportunities for all" and the strategic planning directions of Russia's higher education system. It is concluded that there is a set of problems in the global agenda implementation due to the regional specifics of the formation and development of Russia's higher education system.
\end{abstract}

\section{Introduction}

The paradigm of sustainable development, which has developed over the past halfcentury, has updated research in methodology for analyzing and evaluating the role of individual sectors (branches) of the economy in achieving the Sustainable Development Goals (SDGs) $[2,5$, etc.]. The most systematic Document defining the framework for sustainable development, which formalized the movement process, indicators and criteria, as well as expected results, is the act "Transforming our World: the 2030 Agenda for Sustainable Development" adopted at the conference in New York in 2015. The idea of transforming public relations into a fairway of sustainable development is to harmonize three spheres: social, economic and environmental.

The transition to sustainable development is impossible without the balanced development of countries' individual territories. That issue is more acute in federal states. The sustainable development of the national ecosystem necessitates the creation of an effective spatial ideology for the global agenda implementation.

This paper is devoted to assessing the role of Russia's higher education in achieving the Sustainable Development Goals. The task set in the research involves the use of the spatial context of studying the higher education system. It should be noted that, at the moment, the service industries have turned out to be leaders in terms of their contribution to social and economic development (employment, capacity, the level of preservation and development of local cultures) of both the national economy and the economy of the country's individual

\footnotetext{
${ }^{*}$ Corresponding author: eskulikova@ mail.ru
} 
territories. Higher education is no exception. In most cases, the regions with the most developed higher education system are the territories of attraction of a highly qualified labour force.

Within the framework of the 17 UN Sustainable Development Goals defined, 232 indicators have been identified, according to which the achievement of the tasks of the Global Agenda can be assessed. In order to develop education in the context of sustainable development, the "Incheon Declaration and Framework for Action for the Implementation of Sustainable Development Goal 4" were adopted. Education 2030" [1].

\section{Sustainable Development Goals}

Let's correlate the UN Sustainable Development Goals and the modern goal-setting of higher education. In the context of this research, the fourth goal is the most significant among the other seventeen Sustainable Development Goals: "Ensure inclusive and equitable quality education and promote lifelong learning opportunities for all". Within the framework of this goal, there are seven tasks and three mechanisms for achieving them. To specificate the fourth goal, the guide "Unpacking Sustainable Development Goal 4 Education 2030" was created [4]. We emphasize that the importance of education is not limited to the fourth goal and in one way or another contributes to the implementation of other SDGs.

The analysis of the tasks set by the Agenda shows that in the context of the stated topic, special attention should be paid to target 4.3 "By 2030, ensure equal access for all women and men to affordable and quality technical, vocational and tertiary education, including university". We will highlight some accents made by the developers of the Global Agenda:

- $\quad$ education is classified as a public good, which implies the responsibility of the state in this sphere and determines the key characteristics of the education service: noncompetitiveness, non-exclusivity, trust-based nature, public funding.

- $\quad$ the need to ensure the possibility of obtaining professional education (including higher education) through life is fixed;

- $\quad$ a gradual transition to free higher education is expected;

- the document "Towards 2030: a new vision for education" establishes countries' obligation to increase the level of education funding to ensure its quality.

The three mechanisms for achieving goals contain the following algorithms:

- create an infrastructure that ensures equal access to education at all levels (including higher education) for people with disabilities, create an expanded inclusive environment in education;

- increase the number of scholarships in general and for developing countries in particular;

- $\quad$ big up teachers' status by their professional training and ensuring a decent salary.

As strategic directions for the development of higher education in the context of sustainable development, the following are proposed:

- $\quad$ strengthen the relationship between science and education, strengthen the research functions of universities;

- $\quad$ expand the involvement of employers and trade unions;

- $\quad$ develop open education (distance and correspondence forms);

- $\quad$ strengthen international cooperation and cross-border education.

In the context of the study of higher education role in the implementation of sustainable development, we additionally note target 4.6 on the need for meaningful content of educational programs to form students' knowledge and skills in sustainable development (for example, environmental disciplines, promotion of cultural diversity and respect for human rights, etc.). 
The assessment of the strategic documents devoted to education in general and higher education, in particular, allows noting that the current National Project "Education" does not pay attention to the entire higher education system but only to its individual functions, considering it as economic infrastructure but not as an independent object of management. Based on the aforesaid, we can state the absence of a unified system of goals and indicators for the development of the entire higher education system.

The implementation of the sustainable development agenda in regulation and strategic planning in Russia is not carried out systematically. There is no direct consolidation of goals, no area of responsibility of a particular authority for implementing a specific goal, no obligation to reflect indicators of each goal in regulatory acts.

\section{Findings and Discussion}

The analysis of goal-setting in education allows noting that most of the tasks and directions of development are reflected in one way or another in the National Project "Education" and other documents. As the Accounts Chamber of Russia notes [6], the annual messages of the President of the Russian Federation contain provisions directly related to the implementation of the fourth goal. The least realized target in the higher education system is the one of training personnel with competencies in implementing the principles of sustainable development (for example, promoting environmental conservation, resource conservation). In the information provided by the Ministry of Science and Higher Education, there is no data on the implementation of instructions in this sphere [6]. Monitoring the implementation of the Sustainable Development Goals in general, and the role of education, in particular, is also not perfect. At present, the largest share of indicators that are not subject to monitoring but fixed as recommended in UN documents relates to the implementation of the fourth goal and is $64 \%$ according to the Accounts Chamber of Russia.

The Federal State Statistics Service presents reports on five indicators, three of which characterize, among other things, higher education (Figure 1).
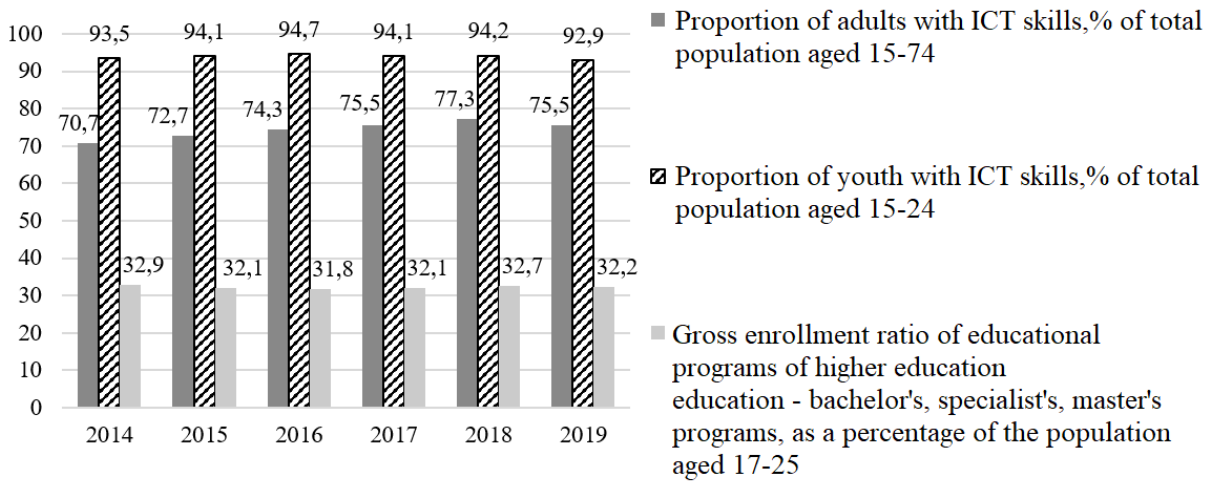

Proportion of adults with ICT skills, \% of total population aged $15-74$

Proportion of youth with ICT skills, $\%$ of total population aged 15-24

Gross enrollment ratio of educational programs of higher education education - bachelor's, specialist's, master's programs, as a percentage of the population aged $17-25$

Fig. 1. Data of the Federal State Statistics Service demonstrating the implementation of Sustainable Development Goal 4 [7]

The state policy in higher education, which led to a decrease in the number of educational institutions of higher education according to the results of performance monitoring conducted in 2014-2017 among non-state universities by $31.5 \%$, budget ones - by $18.3 \%$, provoked a significant decrease in the number of students in the country, which is not consistent with the sustainable development agenda. The share of adults and young people who have the skills to use information technologies also decreased slightly. 
It should be noted that along with the UN calls to expand the possibility of distance education, this form of education is reduced intensively in the country by excluding the possibility of obtaining education in this form from the Federal State Educational Standards (FSES) (for example, the FSES of the thirty-eighth enlarged group "Economics and Management").

The problem is to ensure equal access to higher education, the level of which is decreasing under the conditions of regional differentiation of Russia's educational space, which is expressed in the uneven placement of universities on the territory. In particular, currently, only 15 regions have more than ten educational institutions of higher education on their territory. In total, twenty regions of the country have one or two universities. At the same time, more than $50 \%$ of Russian students study in 12 regions of the country.

A problematic issue is the filling of Russian higher education with competencies in sustainable development. It should be noted that, in retrospect, environmental higher education developed in the mid-nineties with the intensification of the adoption of environmental legislation and the formation of state structures whose area of responsibility included the development of this sphere. However, currently, there is no unified system of environmental education. Most of the competencies in this area are formed at school and in the system of non-formal education.

\section{Conclusions}

Considering higher education services as a public good in the documents on sustainable development doesn't improve at present either. In Russia, a stable approach to higher education seems to have been formed as a patronized good, the demand for which is supported by the state, including by co-financing and allocating state-funded places. Without delving into the discussion about the attribution of higher education services to public goods (this is written about in many scientific sources [3]), we emphasize that there are no plans to switch to universal free higher education in Russia soon.

Thus, it should be noted that the global agenda of sustainable development is being implemented in Russian education with different levels of success, which is due to the regional specifics of Russia and the national peculiarities of the development of higher education. In particular, the planned decrease in the number of external students and higher education providers is dictated by the overheating of the education market and a decrease in its quality. Russia is one of the few countries with a significant imbalance of intramural and extramural forms of education, formed during intensive industrialization, which led to the demand for on-the-job training.

The above is also characteristic of reducing the number of educational organizations, which seems appropriate in the context of a widespread decline in its quality and to preserve the most effective universities.

And it is obvious that during the implementation of the Sustainable Development Goals the regional specifics of a country and the peculiarities of its social, cultural and historical development should be taken into account.

\section{References}

1. Incheon Declaration and Framework for Action for the implementation of Sustainable Development Goal 4

2. P. Nijkamp, P. Laschuit, F. Soeteman, Sustainable development in a regional system (Serie Research Memoranda; No. 1991-93), Faculty of Economics and Business Administration, Vrije Universiteit Amsterdam (1991) 
3. Shelley R. Price-Williams, Roger "Mitch" Nasser, Pietro A. Sasso, The Competition of an American Public Good: Performance-Based Funding and Other Neoliberal Tertiary Effects in Higher Education, Leadership Strategies for Promoting Social Responsibility in Higher Education, 175 (2020). 10.1108/S2055-364120200000024015

4. Unpacking Sustainable Development Goal 4 Education 2030. https://planipolis.iiep.unesco.org/sites/default/files/ressources/246300e.pdf

5. K. Vladimirova, D. Le Blanc, Sust. Dev., 24, 254 (2016). doi: 10.1002/sd.1626

6. Bulletin of the Accounts Chamber of the Russian Federation, 2020, No. 6. Sustainable Development Goals. https://ach.gov.ru/upload/iblock/b06/b065c140de24fbc32271bb2267f621ec.pdf

7. Federal State Statistics Service. https://rosstat.gov.ru/

8. E. Abad-Segura, M. González-Zamar, J. C. Infante-Moro, G. R. García, Sustainability (Switzerland), 12(5) (2020). doi:10.3390/su12052107

9. M. Aleixo, U. M. Azeiteiro, S. Leal, Int. J.of Sustainability in Higher Educ. 21(2), 336 (2020). doi:10.1108/IJSHE-04-2019-0150

10. G. Cebrián, M. Junyent, I. Mulà, Sustainability (Switzerland), 12(2) (2020). doi:10.3390/su12020579

11. H. Kopnina, J. of Environmental Educ. 51(4), 280 (2020). doi:10.1080/00958964.2019.1710444

12. A. Nousheen, S. A. Yousuf Zai, M. Waseem, S. A. Khan, J. of Cleaner Production, 250 (2020). doi:10.1016/j.jclepro.2019.119537

13. Obaid AI-Youbi, A. Al-Hayani, H. J. Bardesi, M. Basheri, M. D. Lytras, N. R. Aljohani, Sustainability (Switzerland), 12(11) (2020). doi:10.3390/su12114367

14. K. Shulla, W. L. Filho, S. Lardjane, J. H. Sommer, C. Borgemeister, Int. J.of Sustainable

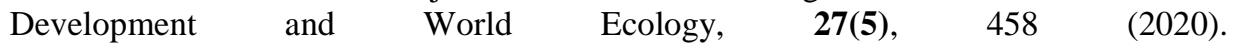
doi:10.1080/13504509.2020.1721378 